\title{
Forecasting of the number of bird collisions with turbines in the territory of Pre-Azov region wind park using the route census method
}

\author{
Volodymyr Yeremieiev ${ }^{1, *}$ \\ ${ }^{1}$ Bogdan Khmelnitsky Melitopol State Pedagogical University, 20 Hetmanska Str., Melitopol, 72300, Ukraine
}

\begin{abstract}
The information system has been designed to ensure the analysis of information on the monitoring results of the wind power plant (WPP) territory using the route census method. The database contains 48 fields, reflecting the monitoring results of birds' behavior in the territory of WPP and processing the initial data: year, month and day of observation, a number of birds of this species, flight altitude, flight speed, direction of flight, coordinates of the bird registration point on the Google-map, average number of birds flying over the territory of the wind park at a given time, coordinates of the points of intersection of the bird flight path with the perimeter of the wind park or observation site, the length of bird flight path over the observation site, and other parameters. The analysis of distribution of birds in the territory of the "Primorsk1" WPP according to the types of migration (forage, transit, nesting, and ground), direction of flight and altitude characteristics has been carried out. The total number of registered birds was 8927 specimens of 72 species, of which 802 specimens of 11 species were referred to the transit type, 2511 specimens of 32 species - to the forage type, 5614 specimens of 60 species were on the ground (ground type). Most birds (63\%) belong to the ground type. $28 \%$ of birds were registered in the forage group, $9.0 \%$ of birds were flying in transit. The greatest activity of birds is manifested in the autumn migration season, when the transit group accounts for $77 \%$ of all annual transit flights. The proportion of birds of forage and ground types, registered in autumn, is $68 \%$ and $74 \%$, respectively, of the total number of birds registered in autumn. In the group of ground birds, the overwhelming majority of specimens belong to the period of autumn migration (4141 birds or $74 \%$ ). The least number was observed in the winter season (317 birds or 5.6\%). The author proposes a mathematical model for analyzing birds' interaction with turbines using the results of monitoring the territory of wind power plants by means of route census method. The model makes it possible to obtain information on the probability of different species of bird collisions with wind wheels and the number of collisions with turbines, depending on the flight characteristics of birds, parameters of wind parks and observation conditions in different seasons. In the risk zone of birds' interaction with turbines, only specimens of one species, Buteo buteo, were observed. The calculated probability of one bird collision when passing through the wind wheel is 0.19 . The anticipated number of bird collisions with turbines during one year of the "Primorsk-1" wind park functioning is in the range of $5.6 \div 6.7$ specimens.
\end{abstract}

\section{Introduction}

The intensive development of wind energy has a certain impact on the environmental situation, especially noticeable in cases where wind power plants are located in places where bird communities are concentrated. The negative impact of wind turbines on ornithofauna is of global concern [9] [13] [24] [26]. According to the data [17], eleven wind power plants at the Spanish station in Navarro 20.6 vultures and several thousand of small birds are killed by one turbine annually. Only in two regions of Spain in the period from 1993 to 2016 the number of dead birds of 170 species and bats were 10,017 specimens [23]. Winkelman [27] reports that mortality rates of large birds on the coast are estimated at 2.4-56.2, and for passerines at 2.1-63.8 specimens/ turbine/year. In the territory of the wind power plant in the United States, 140.000-328.000 birds [18] and $0.5 \div 1.6$ million bats [8] die annually.

The territory of most of the used and projected wind power plants in Ukraine is located on the Azov and Black sea coasts. In 2020, the energy company DTEK completed the construction of the second stage of the Primorsky wind park in the Zaporozhye region next to the operating $200 \mathrm{MW}$ Botievo WPP. Earlier, in May, the first stage of the station, which is located near the city of Primorsk, was launched (Primorsk Wind Park, 2020). Migratory bird complexes of the Azov-Black Sea ecological corridor are characterized by a great diversity in species composition, large-scale in numbers in Eastern Europe and they are significant in the number of rare and endangered species, which are protected by the Bonn Convention and the Agreement on the Conservation of

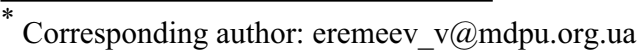


Migratory Birds on the Afro-Eurasian Transcontinental Routes [6]. Therefore, the study of transcontinental migration flows is extremely important for assessing possible negative impact of wind power plants on the behavior of birds in the territory of wind power plants and adjacent zones.

The foundations of the analysis and, in particular, the anticipation of the state of the birds' biodiversity in the studied territories are the results of long-term monitoring. The methodology for the anticipation of the number of bird collisions with wind turbines is described in the recommendations of the Scottish Natural Heritage Foundation (Scottish Natural Heritage, 2014). The reliability of these recommendations has been confirmed by many researchers [16] [20] [15] [21]. The recommendations of the Scottish Natural Heritage Foundation provide for monitoring at several stationary sites belonging to the wind power plants. The size of the selected sites, as a rule, does not exceed $10 \div 20 \%$ of the total area of the wind park.

The deployment of wind power facilities in one of the most powerful migration routes in Eastern Europe predetermines the need to study the state of biodiversity in the territories of the wind power plants. Project work to substantiate the impact of WPP on the ornithological bird complexes within Primorsk district of Zaporozhye region was carried out in 2011-2017 [1] [6] using the recommendations of the Scottish Natural Heritage fund. Based on the data obtained, the analysis of the possibility of bird death due to their collision with the rotor blades at the "Primorsk-1" wind power plant was carried out [4].

An alternative way to obtain information is the route census method, adapted by Siokhin V.D. and Gorlov P.I. in relation to collecting data necessary to anticipate the impact of wind power plants on the environmental situation [3] [7]. The route census method allows collecting information on the behavior of birds from almost the entire territory of the wind power plant, therefore, in this scientific work, this method is used as a main one. The obtained statistical data processing is not possible without the involvement of modern computer technology. In the scientific works [1] [4] [6] [21] [25] information systems and ornithological databases have been created to ensure the storage and analysis of the results of bird calculations in the Pre-Azov region in 2015-2020. The given research work is devoted to the development of these studies in relation to the monitoring of bird complexes in the territory of "Primorsk-1" wind park using the route census method.

\section{Aim and methodology of research work}

1. Research work aim. The aim of the research work is to anticipate the interaction of birds with the turbines of the "Primorsk-1" WPP, based on the analysis of the results of monitoring the territory of the "Primorsk-1" wind park, which was carried out in 2018 using the route census method. To achieve the aim, the following objectives were formulated:
- development of information system to ensure the analysis of information, based on the results of monitoring the WPP territory using the route census method

- identification of birds distribution according to the direction of migration and altitudes in the territory of the "Primorsk-1" station,

- design of a mathematical model for anticipating birds' interaction with turbines, based on the results of monitoring the wind park's territory using the route census method,

- anticipation of the number of bird collisions with turbines in the territory of the "Primorsk-1" wind park.

2. Methodology for monitoring the territory of WPP. The monitoring time was chosen so as to cover all periods of bird's life: winter period 2018.01.25, 2018.02.16, spring migration season 2018.03.10, 2018.03.20, 2018.04.11, nesting period 2018.05.05, 2018.05.23, autumn migration season 2018.09.15, 2018.09.29, 2018.10.13. The observations were made in the morning and evening hours lasting approximately 3 hours each with a total observation time of 63 hours. The scheme of one of the route census, related to the observations of 2018.03.20 and linked to the Google map for the northeastern part of the territory of the "Primorsk-1" wind park, is shown in Fig. 1.

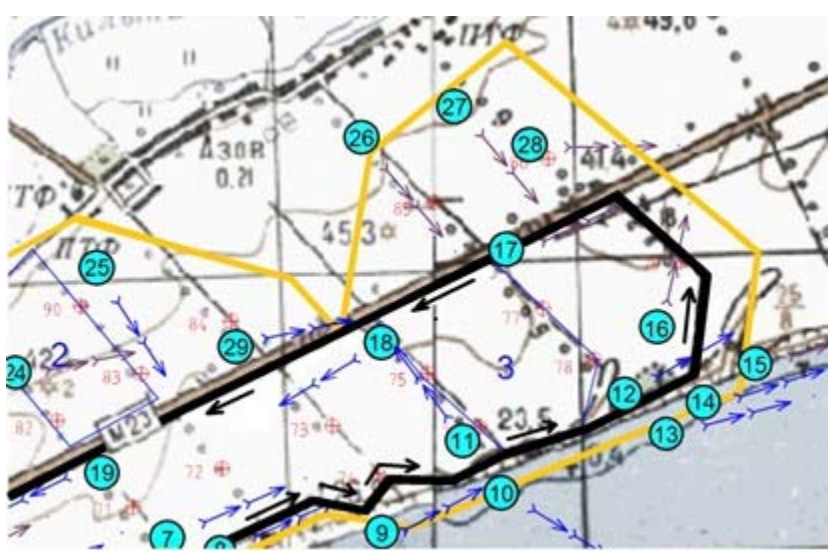

Fig. 1. Scheme of route census 2018.03.20 in the territory of the wind park "Primorsk-1".

The territory of the wind park is an irregular polygon with sixteen vertices; in Fig. 1 its boundary is painted in yellow color. The observer was moving by car at a speed of less than $10 \mathrm{~km} / \mathrm{h}$. The vehicle's trajectory is represented on the map by the segments, painted in black color, the direction of movement is indicated by black arrows. At first, the movement was carried out along the sea coast in a northeast direction. As the observer was moving, he registered several groups of birds in positions with numbers $9 \div 15$, which are circled in Fig. 1 .

For each group of registered specimens, the flight altitude, number of birds of a certain species and direction of migration, which is indicated by arrows on the map, were registered. For example, at the position, marked with the no.9, at 10:00 am, 6 specimens of Podiceps cristatus of the forage type, flying in a northeastern direction at an altitude of $10 \mathrm{~m}$, were registered. This mode is typical for birds that constantly inhabit the wind park's territory or the buffer zones. Approximately $500 \mathrm{~m}$ from the eastern border of the wind power plant, the direction of the route 
has changed first to the north, then to the north-west. Here at 11.00 a.m. in position no.16 at an altitude of $10 \mathrm{~m}$, a flock of 14 specimens of Motacilla alba was found. This group of birds was flying in a northeastern direction. Then the route continued in a southeastern direction, where various specimens were observed at positions no.17-19. After reaching the southeastern part of the wind park territory, the route turned north, passed along its northern part, turned south and returned to its western boundaries.

Route census method covered about $75 \%$ of the wind power plant's territory, which is several times larger than the area of sites that are usually involved in the method ("Scottish Natural Heritage", 2014). The monitoring results, obtained by the route census method, contained the following data on the behavior of birds in the WPP territory: season, month, day and hour of registration; place of registration, linked to a Google map; number of birds; bird species; flight direction; type of stay in the territory of WPP (transit, forage, ground); flight altitude. An example of the monitoring results, using the route census method, is presented in table. 1 .

Table 1. Monitoring results of number of n-birds of forage type in the territory of "Prymorsk-1" wind park 2018.01.25 NE - northeast, $\mathrm{S}$ - south, SW - south-west.

\begin{tabular}{|c|c|c|c|c|c|c|}
\hline No & Time & Sprcies & $\mathbf{N}$ & $\begin{array}{c}\text { Type of } \\
\text { migration }\end{array}$ & $\begin{array}{c}\text { Altitude } \\
(\mathbf{m})\end{array}$ & Direction \\
\hline 1 & 11.00 & Sturnus vulgaris & 25 & forage & 7 & NE \\
\hline 2 & & Buteo lagopus & 1 & forage & 30 & $\mathrm{~S}$ \\
\hline 3 & & Larus cachinnans & 18 & forage & 15 & $\mathrm{NE}$ \\
\hline 4 & 12.00 & Larus cachinnans & 21 & forage & 10 & $\mathrm{NE}$ \\
\hline 5 & & Fringilla coelebs & 20 & forage & 5 & $\mathrm{SW}$ \\
\hline 6 & 14.00 & Larus cachinnans & $7,3,2,2$ & forage & 10 & $\mathrm{SW}$ \\
\hline 7 & & Larus cachinnans & $1,1,5,3,4,4$ & forage & 10 & $\mathrm{SW}$ \\
\hline 8 & 16.00 & Buteo lagopus & 1 & forage & 30 & $\mathrm{SW}$ \\
\hline \multicolumn{2}{|l}{ Total } & 5 species & 118 & & & \\
\hline
\end{tabular}

Similar tables contained the results of the registration of migratory flows of birds, which were carried out in 2018.

3. Methodology for processing observation results. The processing of monitoring results should provide information on the behavior of birds in the territory of WPP according to the basic characteristics, which are necessary to anticipate the impact of wind power plants on ornithocomplexes [3] [6] [21] [25], namely:

- a number of birds of the observed species in the territory of the wind park in different seasons of the year,

- distribution of birds by altitude,

- time, spent by birds in the risk zone (RZ) of collision with wind turbines,

- probability of bird collision with the turbine blades when it is in RZ,

- anticipated number of bird-turbine collisions.

The probability of a collision of a bird of the $\mathrm{j}$ species with turbine blades when it is flying through the danger zone of a wind park is [11] [12]:

$$
P_{j}=p_{j}(r, \phi) r d r d \phi / \pi R^{2},
$$

where

$p_{j}(r, \varphi)$ - probable density of a bird collision,

$r$ - distance from a bird to the turbine center,

$\varphi$ - angle of turbine blade rotation,

$R$ - radius of the turbine wind wheel.

The danger zone (ZD) is a part of the area of the entire wind power plant, where the rotating turbines are located. The cubage of the danger zone is

$$
V_{Z d}=M \pi R^{2} d \cos (\gamma)
$$

where

$M$ - a number of turbines in the station territory,

$d$ - average value of the width of the wind wheel blade,

$\gamma$ - blade wedge angle between its chord and the plane of rotation of the wind wheel.

Let $n_{j Z d}$ birds of $j$-species are flying through ZD. Then the number of their collisions with the turbine blades is identified by the formula

$$
n_{j}=f n_{j Z d} P_{j}
$$

where

$f$ - coefficient of evasion, which determines the ability of the bird to change the direction of flight near the wind wheel and, thus, to avoid collision with it; the most probable value of the coefficient $f$ is in the range 0.05 $\div 0.005$ (May, Hoel, \& et al, 2010; Furness, 2015),

$P_{j}$, - probability of collision of birds of $j$-species, flying through the turbine, is identified by formula (1).

Let us introduce the concept of risk zone (RZ) of interaction of birds with rotors. Under RZ we mean a part of the space in the interval of altitudes $\delta H=H_{2}-H_{l}$ between the lower $H 1$ and upper $H 2$ levels of the turbine wind wheel on the observation site with the area $S_{R z}$. The cubage of the risk zone $V_{R z}$ is

$$
V_{R z}=\delta H S_{R z}
$$

Let during the monitoring of $T_{R z} i$-groups of birds of $j$ species were taken into account in the number of $n_{i j}$, each of which was in RZ during $t_{i j}$. The total number of birds of $j$-species $n_{j D z}$, flying through $R Z$ during the operation of the station is (Band, W., 2000; Osadchyi V. et al. 2019) 


$$
n_{j D z}=\frac{V_{D z} T_{L c}}{T_{R z} V_{R z}} \sum_{i} n_{i j} l_{i j}
$$

where

$l_{i j}=t_{i j} v_{j}$ - length of the bird's trajectory at the observation site,

$t_{i j}$ - time of bird's flight over the observation site with a speed $v j$,

$T_{L c}$ - duration of bird's life cycle during the wind park functioning for some time.

Substituting the values of $V_{D z}$ and $V_{R z}$ from formulas (2), (4) into (5), we obtain

$$
n_{j D z}=\frac{M \pi R^{2} \cos (\gamma) d T_{L c}}{T_{\mathrm{Rz}} \delta H S_{R z}} \sum_{i} n_{i j} l_{i j}
$$

According to formulas (3) and (6), the number of collisions of birds of $j$-species with turbine blades is identified by the formula

$$
n_{j}=\frac{M \pi R^{2} \cos (\gamma) d T_{L c} f P_{j}}{T_{\mathrm{Rz}} \delta H S_{R z}} \sum_{i} n_{i j} l_{i j}
$$

The value of the integral (1) is estimated by the formula [21]:

$$
P_{j}=\left[\pi R_{0}^{2}+6\left(R-R_{0}\right) L_{2 j} / \pi+3\left(R-R_{0}\right) d+3\left(R-R_{0}\right)^{2} \omega t / 2\right] /\left(\pi R^{2}\right),
$$

where

$L_{2 j}$ - wingspan of the bird,

$\omega$ - angular speed of turbine rotation,

$R_{0}$ - radius of the rotor sleeve where the blade is attached,

$T$ - time of flight of $j$-species bird through the rotor with speed $v$.

The time of flight $t$ is identified by the formula

$$
\left.t=\left(d \sin (\gamma)+L_{1 j}\right)\right) / v,
$$

where

$L_{l j}$ - length of the bird.

The distance from the ground to the bottom of the rotor is $H 1=48 \mathrm{~m}$, to the top $-H 2=182 \mathrm{~m}$. The blade length is $67 \mathrm{~m}$, the width at the widest point is $4.1 \mathrm{~m}$, maximum rotation speed of the wind wheel is $14 \mathrm{rpm}$. The shape of the observation site can be represented as a circle with an area of about $1 \mathrm{~km}^{2}$, in the center of which the observer is located.

\section{Results of work}

1. Description of the developed information system Birds2. The designed program ensures the storage and processing of data, obtained during monitoring the wind park's territory using the route census method. The program code is based on Windows Forms technology in the Microsoft Visual Studio Community 2019 software development environment. Initiating the program execution displays the main window. In its upper part there are three tabs "Database", "Calculation", "Request", which provide switching the execution of commands between program blocks. When you start the program, the "Database" tab is displayed by default. It contains the dataGridView element with the original data.

Information is loaded into the spreadsheet automatically from the database file of Microsoft Access "birds 2.mdb", which is located in the folder with the executable file "Birds2.exe". The spreadsheet contains information on the results of monitoring the behavior of birds in the territory of the wind power plant and processing the obtained data. It consists of 48 fields:

1. Code - serial number of the record in the database.

2. Date - year, month and day of observation.

3. No. - number, corresponding to the entry on the Google map.

4. Time - time of observation.

$5 . t$-duration of observation in hours for the selected observation day.

6. Species - birds belonging to definite species.

7. Number - number of birds.

8. Type of migration - the way of birds' movement and their presence on the observation site

(transit, forage, nesting).

9. Altitude $(\mathrm{m})$ - flight altitude in $\mathrm{m}$.

10. Speed ( $\mathrm{km} /$ hour) - bird's flight speed in $\mathrm{km} / \mathrm{h}$.

11. Direction - flight direction (N - north, NE northeast, NW - north-west, W - west, SW - southwest, E - east, SE - south-east, S - south).

12. $t g$ - tangent of the angle between the direction of flight and the abscissa axis.

13. $t \mathrm{u}(\mathrm{km})$ - coordinates of the bird registration point on the Google-map on the abscissa axis in $\mathrm{km}$.

14. $v(\mathrm{~km})$ - coordinates of the bird registration point on the Google-map along the ordinate in $\mathrm{km}$.

15. $x 1 \div x 16$ - sixteen coordinates on the abscissa axis in $\mathrm{km}$ for the points of intersection of the bird's flight path with all lines that pass through the sides of the polygon that are the boundaries of the wind power plant.

16. $y 1 \div y 16$ - sixteen coordinates on the ordinate axis in $\mathrm{km}$ for the points of intersection of the bird's flight path with all lines that pass through the sides of the polygon that are the boundaries of the wind power plant.

17. Number - the number of sides of the polygon, which are intersected by birds' flight paths at the entrance and exit of the wind power plant.

18. Length of flight - the average number of birds, flying over the territory of the wind park at a given time.

When the program starts, the display shows the original information, contained in the data file. In the lower left corner of the spreadsheet, information is displayed about the number of records contained in the spreadsheet in the "Database" tab. The spreadsheet is viewed by scrolling the mouse wheel or moving the slider in the horizontal and vertical directions in the lower and right parts of the window using the arrow keys "left", "right", "up", "down".

The coordinates of the points of intersection of the bird's flight path with the boundary of the wind park territory are determined automatically using a specially 
created calculation block. The color of the active (highlighted) line determines the type of migration: blue indicates the type "forage" or "transit", green indicates the type "ground".

In the lower right part of the main window there is a button "Calculation". Pressing this button you start the process of calculating the number of birds of the transit type of flight (Ktr), forage type of flight (Kforage), ground type (Kground) and the total number of birds (Ksum). The $K$ index denotes a calculated parameter that characterizes the average value of the number of birds present in the wind park at a given time. The value of $\mathrm{K}$ could be obtained based on the results of photographing the territory of the wind park from a flying vehicle. If $M$ birds are found in $\mathrm{m}$ photographs of this kind, then the value of the parameter $K$ is equal to the ratio $M / m$. To calculate the value of $K$, a special program block is drawn up.

The calculation results are displayed on the screen in the form of a message window.

Next to the "Calculation" button is the "Map" button. It opens a new window designed for viewing a Google map, indicating the boundaries of the wind power plant in yellow color, the route of observation and places of observation of birds. To display the map on the screen, you must press the "Select file" button in the upper right corner of the window. A dialog box will appear on the screen, in which you should specify the path and select the file with the "jpg" extension for viewing. A map will appear in the center of the screen. Under the button "Select file" there is an element "label", which reflects the coordinates $(\mathrm{km})$ of the mouse cursor on the map.

Clicking the left mouse button at a certain point on the map is resulted in the appearance of a red cross under the cursor. The coordinates of the marked point will be displayed above the "Add coordinates" button. This button copies the coordinates to the " $u(\mathrm{~km})$ " and " $v(\mathrm{~km})$ " fields of the spreadsheet located in the "Database" tab of the main window. The selected coordinates are copied to the active (selected) table row. Information in the active line is displayed in the lower part of the "Map" window (entry code, entry date and number that corresponds to the designation of the entry on the map). The "Map" window is also used for the initial filling in the " $u(\mathrm{~km})$ " and " $v(\mathrm{~km})$ " fields.

In the second tab of the main window "Calculate" there is a spreadsheet that reflects the data, calculated on the basis of the entries of the first spreadsheet in the "Database" tab for a specific direction and altitude of birds' flight. Namely:

- a number of bird species;

- a total number of birds;

- a number of birds of forage type, transit type and nesting type;

- an average number of birds in the territory of the wind park at a given time.

At the bottom of the tab the information about dates of various types is displayed:

- a date or dates that were requested in the "Request" tab;
- a date or dates that meet the conditions of the request;

- a date or dates that meet the conditions of this request and are referred to the entries with the "forage" and "transit" flight types.

Calculations are carried out on the basis of a request for the entries using the third tab "Request", where the forms that ensure the fulfillment of the conditions for selecting data from the spreadsheet from the tab "Database" are displayed. The choice is made according to four parameters:

- species of birds;

- flight date;

- direction of flights;

- type of flights.

Sample request provides a selection of all registered birds of a transit type in the territory of the wind park that were flying in 2018.09.15 in a western direction. The choice of initial data is carried out using the forms in the headings "All values" or "Selectively". "Selectively" mode defines a list of selected parameters from the existing options. Installation of one or several arbitrary options is allowed.

After setting the request, you have to leave the "Request" tab and go to the "Database" or "Calculate" tab. The program automatically performs all actions in accordance with the request. Information from the database that meets the set request is displayed in the "Database" tab, and a number of birds is displayed in the lower right corner of this tab. After the user leaves the "Request" tab, the data from the "Calculation" tab are automatically recalculated in accordance with the new information from the "Database" tab.

2. Distribution of birds by types of migration and altitudes. The total number of registered birds was 8927 specimens of 72 species, of which 802 specimens of 11 species were of the transit type, 2511 specimens of 32 were of the forage type, 5614 specimens of 60 species were of the ground (terrestrial type). 4 birds Buteo buteo were registered in the risk zone of the collision with turbines (RZ). The quantitative characteristics of birds of various types according to the season are given in table 2 .

Table 2. Distribution of birds by type of migration.

\begin{tabular}{|c|c|c|c|c|c|}
\hline $\begin{array}{c}\text { Type of } \\
\text { migration }\end{array}$ & $\begin{array}{c}\text { Winter } \\
\text { season }\end{array}$ & $\begin{array}{c}\text { Spring } \\
\text { migration }\end{array}$ & $\begin{array}{c}\text { Nesting } \\
\text { season }\end{array}$ & $\begin{array}{c}\text { Autumn } \\
\text { migration }\end{array}$ & Total \\
\hline Transit & 0 & 128 & 53 & 621 & $802(9,0 \%)$ \\
\hline Forage & 277 & 375 & 162 & 1697 & $2511(28 \%)$ \\
\hline Ground & 317 & 592 & 564 & 4141 & $5614(63 \%)$ \\
\hline
\end{tabular}

As it can be seen from table 2, a majority of birds $(63 \%)$ belongs to the ground type. In the forage group $28 \%$ of birds were registered, the remaining $9.0 \%$ of birds were flying in transit. The greatest activity of birds is manifested in the autumn migration season, when the transit group accounts for $77 \%$ of all annual transit flights. The proportion of birds of forage and ground types, registered in autumn, is $68 \%$ and $74 \%$, respectively, of the total number of birds registered in autumn. Data on the number of species and number of 
birds of the ground type in different seasons are given in table 3 .

Table 3. Distribution of birds by type of migration.

\begin{tabular}{|c|c|c|c|c|}
\hline Season & $\begin{array}{c}\text { Winter } \\
\text { season }\end{array}$ & $\begin{array}{c}\text { Spring } \\
\text { migration }\end{array}$ & $\begin{array}{c}\text { Nesting } \\
\text { season }\end{array}$ & $\begin{array}{c}\text { Autumn } \\
\text { migration }\end{array}$ \\
\hline $\begin{array}{c}\text { Number of } \\
\text { species }\end{array}$ & 13 & 25 & 35 & 43 \\
\hline $\mathrm{N}$ & 317 & 592 & 564 & 4141 \\
\hline
\end{tabular}

Of the total number of ground type birds, the largest part of them belongs to the period of autumn migration (4141 or $74 \%$ ). The least number was registered in the winter season (317 birds or 5.6\%).

Analysis of migratory flows showed that only 277 specimens of six species of the forage group were flying by in winter. At an altitude of up to $10 \mathrm{~m}, 66 \%$ of birds were registered, in the range of altitude $(11 \div 25) \mathrm{m}-32 \%$, in the range of altitude $(26 \div 50) \mathrm{m}-2 \%$. There were no birds in the risk zone.

The spring migration period was distinguished by a higher diversity of species. The forage group included 375 birds of 22 species, the transit group -128 birds of 6 species. In RZ, at an altitude of $100 \mathrm{~m}$, two forage-type Buteo buteo birds were found. In the range of altitude $(26 \div 50) \mathrm{m}$, one bird was registered, in the range of altitude $(11 \div 25) \mathrm{m}-40$ birds $(8 \%)$, the remaining 460 specimens $(91 \%)$ were flying at an altitude of up to $10 \mathrm{~m}$.

During the nesting period, 162 birds of 10 species of the forage group and 53 birds of one species L.melanocephalos of the transit group were counted in flight. No birds were found in RZ. At an altitude of up to $10 \mathrm{~m}, 134(62 \%)$ birds were flying by, in the range of altitude $(11 \div 25) \mathrm{m}-40(8 \%)$, in the range of altitude $(26 \div 50) \mathrm{m}-70$ specimens $(32.5 \%)$.

The total number of migratory birds in the autumn period was 2318 , belonging to 26 species. Out of these, 1697 specimens of 21 species belonged to the forage group, 621 specimens of 8 species - to the transit group. $1591(68.6 \%)$ birds were flying at an altitude of up to $10 \mathrm{~m}$, in the range of altitude $(11 \div 25) \mathrm{m}-173(7.5 \%)$, in the range of altitude $(26 \div 50) \mathrm{m}-350(15.1 \%)$ birds. In RZ, at an altitude of $150 \mathrm{~m}, 2(0.1 \%)$ Buteo buteo birds of the forage type were found, $202(8.7 \%)$ specimens were flying above $150 \mathrm{~m}$.

Thus, out of 72 species in RZ, only one species, Buteo buteo, was registered in the amount of 4 birds. During the monitoring period, 16 representatives of this species were registered, most of which were outside the RZ.

Designed program differs from other information systems, described in the scientific works [1] [21] by the ability to identify a number of characteristics of birds of the transit type, which are necessary for the anticipation of their collision with turbine blades:

- coordinates of points of bird's flight path intersection with the perimeter of the wind park or observation site,

- length of the bird's flight path over the territory of the wind park,

- average number of birds flying over the territory of the wind park at a given time.
3. Anticipation of the interaction of birds of the species Buteo buteo with turbines. The results of monitoring the territory by the route census method provide information only about the altitude and direction of flight. Bird migration trajectories are characterized by a great diversity. An example of flight trajectories of specimen, registered in the territory of the "Primorsk-1" wind park, during the autumn migration is shown in Fig. 2.

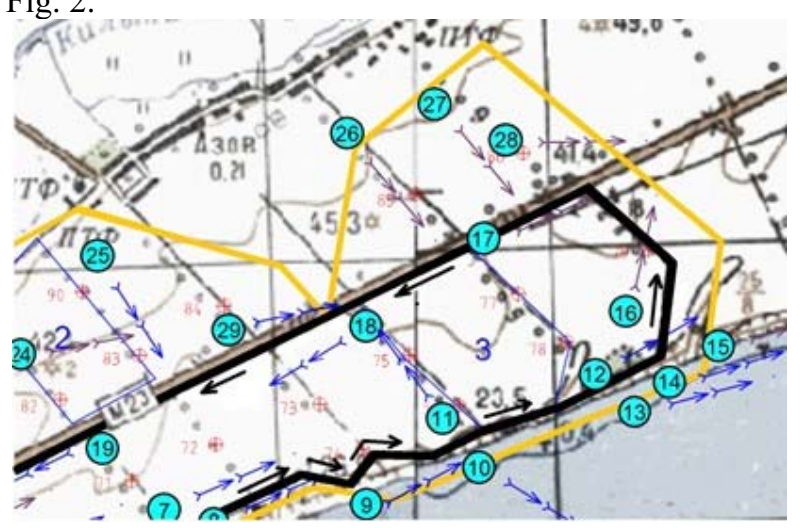

Fig. 2. Sample flight trajectories of specimens, registered in the territory of the "Primorsk-1" wind park during the autumn migration.

At low altitudes, birds usually fly along curved trajectories such as (4), (5) in Fig. 2. The vast majority of birds, registered in RZ and above it, were flying along straight lines (1), (2), (3), (6), (7). In order to estimate the length of rectilinear trajectories $l_{i j}$ in formula (7), we represent the shape of the observation site as a circle of radius r with area $S R z=\pi r 2$, in the center of which the observer is located. The $S R z$ value is about $1 \mathrm{~km} 2$. In this case, the viewing radius $r$ is $560 \mathrm{~m}$. The length of the bird's flight path in the observation site was $880 \mathrm{~m}$. The flight speed was taken to be $v j=11,6 \mathrm{~m} / \mathrm{sec}$.

The $t i j$ value in this case is $75.9 \mathrm{sec}$.

To anticipate the interaction of birds with turbines according to formula (7), we need information on the duration of the bird's life cycle during the year of the wind park functioning. Two cases may arise here:

- a number of bird collisions with turbines is identified in each season separately, taking into account the results of monitoring by seasons,

- a number of bird collisions with turbines is identified during a year, taking into account the total monitoring results for one year.

In both cases, the same formula (7) is used, but due to different values of the parameters TLC (duration of the bird's life cycle) and TRisc (duration of monitoring time), the results will not be the same. With a sufficiently large statistical sample of birds in the RZ, the first case should be preferred. The corresponding data on the value of $T L C$ in different seasons with duration of $T R Z$ in relation to one year of wind park "Primorsk-1" functioning are presented in Table. 4. The duration of a conventionally bright day $\triangle T R z$ when calculating $T L C$ was taken equal to 8 hours for the winter season, 10 hours for the autumn season, and 12.5 hours for the spring and nesting seasons. 
Calculations were carried out for the following values of WPP parameters and characteristics of Buteo buteo birds: maximum blade width $d=4.1 \mathrm{~m}$, maximum angular rotation speed of the wind wheel $\varpi=14 \mathrm{rpm}$, wind wheel radius $\mathrm{R}=67 \mathrm{~m}$, hub radius $T R 0=3 \mathrm{~m}$, angle between the chord of the blade section and the plane of the wind wheel $T \gamma=300$, bird length $L 1 j=0.54 \mathrm{~m}$, wingspan $l 2 j=1.2 \mathrm{~m}$, flight speed $11.6 \mathrm{~m} / \mathrm{s}$. The probability of a bird collision with the blades, calculated by the formula (8) in the case of its flight through the wind wheel, is 0.19 .

The number of collisions during one year of WPP functioning, calculated by the formula (7) for the collision probability $P j=0.19$, taking into account the data in Table 4, equals 3.7 for the spring and 3.0 for the autumn migration season. The total number of collisions was 6.7 .

Table 4. Duration of observations $T R z$, a number of conditional light days $\Delta T R z$ in the season and a phase of the life cycle of birds $T L C$ in hours.

\begin{tabular}{|c|c|c|c|c|c|}
\hline $\begin{array}{c}\text { Cycle of } \\
\text { observation }\end{array}$ & $\begin{array}{c}T R z, \\
\text { hour }\end{array}$ & $\begin{array}{c}T R z, \\
\text { sec }\end{array}$ & $\Delta T R z$ & $\begin{array}{c}T L c, \\
\text { days }\end{array}$ & $\begin{array}{c}T L c, \\
\text { hour }\end{array}$ \\
\hline $\begin{array}{c}\text { Migration in } \\
\text { spring }\end{array}$ & 13 & 46800 & 12,5 & 85 & 1062,5 \\
\hline Nesting & 22 & 79200 & 12,5 & 90 & 1125 \\
\hline $\begin{array}{c}\text { Migration in } \\
\text { autumn }\end{array}$ & 15 & 54000 & 10 & 100 & 1000 \\
\hline Winter season & 13 & 46800 & 8 & 90 & 720 \\
\hline Total & 63 & 226800 & & 365 & 3907,5 \\
\hline
\end{tabular}

Monitoring the territory of the wind park has shown that birds of the species Buteo buteo are found at different altitudes in all seasons. The total number of Buteo buteo birds that were found in the territory of the wind park at all altitudes was 16 . One bird was registered outside the $\mathrm{RZ}$ in winter, seven - during the spring migration period ( 2 in the RZ and 5 outside it), three - during the nesting season and five - in autumn ( 2 in RZ and 3 outside). It can be assumed that, theoretically, in the risk zone of interaction with turbines, birds could appear not only in spring or autumn, but also in winter and nesting periods. Therefore, the registered number of birds in RZ can equally be attributed to any season. In this case, the same formula (13) is valid, but due to the different duration of the bird's life cycle $T L C$ and the duration of the monitoring time TRisc, the results will not be the same. The calculated number of collisions during one year of WPP functioning turned out to be 5.6 specimens, which practically coincides with the calculated value in the first case.

Combining the latest data with previously obtained results, which take into account seasonal differences, we can assume that the most reliable anticipation is the range of values $5.6 \div 6.7$. It is interesting to compare the obtained assessment of the interaction of birds with turbines with the anticipation made in 2017 (Osadchyi V. et al.) which was based on the results of WPP monitoring, carried out in accordance with the recommendations of the Scottish Natural Heritage Foundation, 2014. The anticipated number of collisions per one year of WPP functioning according to the data of the mentioned above research work was about 6.5 birds. the observer is located.

\section{Conclusions}

The Birds2 information system has been developed to ensure the analysis of information, based on the results of monitoring the wind park's territory using the route census method. The program code is compiled on the basis of Windows Forms technology in the Microsoft Visual Studio Community 2019 software environment. The main database contains 48 fields, reflecting the results of monitoring of birds' behavior in the wind park and processing the initial data: year, month and day of observation, an identifier that binds coordinates of the registered bird to the point on the Google-map, time of observation day, observation duration for the selected observation day, bird species, number of birds of this species, type of movement and presence of birds in the observation site, flight altitude, flight speed, direction of flight, coordinates of a point of registration of birds on a Google map, average number of birds flying over the territory of the wind park at a given time and other parameters.

The designed program differs from previously developed information systems in the research works [1] [21] by the ability to identify a number of characteristics of birds of the transit type, which are necessary to anticipate their collision with turbine blades:

- coordinates of points of intersection of the bird's flight path with the perimeter of the wind park or observation site,

- length of the bird's flight path over the territory of the wind park,

- average number of birds, flying over the wind park's territory at a given time.

The analysis of the distribution of birds in the territory of the "Primorsk-1" wind power plant is carried out according to the types of migration (forage, transit, nesting, ground), direction of flight and altitude characteristics. The total number of registered birds was 8927 specimens of 72 species, of which 802 specimens of 11 species were of the transit type, 2511 specimens of 32 species were of the forage type, 5614 specimens of 60 species were on the ground (ground type). Most birds (63\%) belong to the ground type. In the forage group $28 \%$ of birds, $9.0 \%$ of birds were flying in transit. The greatest activity of birds is manifested in the autumn migration season, when the transit group accounts for $77 \%$ of all annual transit flights. The proportion of birds of forage and ground types, registere in autumn, is $68 \%$ and $74 \%$, respectively, of the total number of birds registered in autumn. In the group of ground birds, the overwhelming majority of specimens belong to the period of autumn migration (4141 or $74 \%$ ). The least was registered in the winter season (317 birds or $5.6 \%$ ).

A mathematical model has been developed for analyzing the interaction of birds with turbines using the results of monitoring the territory of wind power plants using the route census method. The model makes it possible to obtain information on the probability of collisions of different species of birds with wind wheels and number of collisions with turbines, depending on the flight characteristics of birds, parameters of wind parks and observation conditions in different seasons. In the risk 
zone of birds' interaction with turbines, 4 birds of the same species Buteo buteo were registered. The probability of a single bird's collision, when passing through the wind wheel, is about 0.19 . The calculated number of collisions of birds with turbines during one year of "Primorsk-1" wind park functioning is within the range of $5.6 \div 6.7$ specimens.

\section{References}

1. Siokhin, V.D., Gorlov, P.I., Annenkov A.B. "Methods for using software for monitoring seasonal bird systems and assessing the impact of wind farms." Branta: Collection of scientific works of the AzovBlack Sea Ornithological Station (2014)

2. Gorlov, P.I., Siokhin, V.D. Analysis of international experience in studying the impact of wind power plants on birds. Biological Bulletin of Bodgan Khmelnytsky Melitopol State Pedagogical University, 1, 37-47.(2012)

3. Gorlov, P.I., Siokhin, V.D., Dolinny V.I., Sidorenko A.I. Seasonal ornithological features of the territory of Botievsky wind power plant (Zaporozhye region) according to the results of observations in the spring periods of 2013-2014. Branta: Proceedings of scientific works of the Azov-Black Sea ornithological station, 17, 19-38. (2014)

4. Osadchyi, V., Yeremieiev, V., \& Osadcha, K. Software for analyzing the probability of collisions of birds with rotors of wind electrical installations. Ukrainian Journal of Educational Studies and Information Technology, 6(4), 1-18. (2018)

5. Primosk WPP. URL: http:https://delo.ua/business/vukraine-zarabotala-odna-iz-krupnejshih-vetrjan359989/ (2020) Accessed 23 Oct 2020

6. Siokhin V.D., Gorlov P.I., Polishchuk I.K., Podorozhny S.M., Dolinna O.M. Conducting modern monitoring research and development of expert conclusion and scientific report on the impact of wind power plants construction on natural environmental complexes, ornithological complexes and migratory birds, bats within the Primorsky district of Zaporozhye region. Melitopol: Research and Production Enterprise "Ekoresurs i monitorynh". (2018)

7. Siokhin V.D., Chenichko J.I., Sidorenko A.I., Gorlov P.I., Aleinikova K.G. Cumulative assessment of the impact of wind power plants on natural complexes in the man-made areas of the north-western Azov Sea. Message 2. Seasonal complexes of birds. Monitoring and protection of biodiversity in Ukraine: Applied aspects of monitoring and protection of biodiversity. Series: Conservation Biology in Ukraine. Chernivtsi: Print Art, 16(3), 152-167. (2020)

8. Arnett, Edward B., and Erin F. Baerwald. "Impacts of wind energy development on bats: implications for conservation." Bat evolution, ecology, and conservation. Springer, New York, NY, 435-456. (2013)
9. Aschwanden, J., Stark, H., Peter, D., Steuri, T., Schmid, B., \& Liechti, F. Bird collisions at wind turbines in a mountainous area related to bird movement intensities measured by radar. Biological Conservation, 220, 228-236. (2018)

10. Band, W., Madders M., Whitfield D.P. Windfarms and Birds: Calculating a theoretical collision $\mathrm{Rz}$ assuming no avoiding action. Guidance note series: Scottish Natural Heritage. URL: https://tethys.pnnl.gov/sites/default/files/publication s/Band-2000.pdf (2012) Accessed 25 Oct 2020 (2000)

11. Band, W., Madders M., Whitfield D.P. Developing field and analytical methods to assess avian collision risk at wind farms. Birds and Wind Farms: Risk Assessment and Mitigation. Ed. by M. de Lucas, G.F.E. Janss \& M. Ferrier. Madrid: Quercus, 259275. (2007)

12. Band, W. Using a collision risk model to assess bird collision risks for offshore windfarms. March, 62. URL: http://surl.li/obyt (2012) Accessed 25 Oct 2020

13. Dai, K., Bergot, A., Liang, C., Xiang, W. N., \& Huang, Z. Environmental issues associated with wind energy-A review. Renewable Energy, 75, 911-921. (2015)

14. Furness, R. W. A review of red-throated diver and great skua avoidance rates at onshore wind farms in Scotland. Scottish Natural Heritage Commissioned Report, 885. (2015)

15. Jervis, L. Offshore Ornithology - Collision Rz Modelling /L. Jervis, S. McGovern, S. Sweeney, R. Buisson // Report Volume 4, Annex 4-2. 2017. https://corporate.vattenfall.co.uk/globalassets/uk/ projects/thanet-ext/peirnov-2017/volume4/vol4ann4-2-ornithologycrm.pdf (2017) Accessed 22 Oct 2020

16. Krijgsveld, K. L., Akershoek, K., Schenk, F., Dijk, F., \& Dirksen, S. Collision risk of birds with modern large wind turbines. Ardea, 97(3), 357-366.(2009)

17. Lekuona, J. M., \& Ursua, C. Avian mortality in wind power plants of Navarra (Northern Spain): 177-192. Birds and wind farms. Risk assesment and mitigation. Servicios Informativos Ambientales/Quercus, Madrid. (2007)

18. Loss, S. R., Will, T., \& Marra, P. P. Estimates of bird collision mortality at wind facilities in the contiguous United States. Biological Conservation, 168, 201209. (2013)

19. May, R., Hoel, P. L., Langston, R., Dahl, E. L., Bevanger, K., Reitan, O. et. al. Collision $\mathrm{Rz}$ in whitetailed eagles. Modelling collision Rz using vantage point observations in Smøla wind-power plant. NINA Report 639, 25. (2010)

20. Morinha, F., Travassos, P., Seixas, F., Martins, A., Bastos, R., Carvalho, D., \& Cabral, J. A. Differential mortality of birds killed at wind farms in Northern Portugal. Bird Study, 61(2), 255-259. (2014) 
21. Osadchyi, V., Siokhin, V., Gorlov, P., Yeremieiev, V., \& Osadcha, K. Development of the information system for forecasting collision between birds and wind farms. Eastern-European Journal of Enterprise Technologies, 4(2 (100)), 29-40. (2019)

22. Scottish Natural Heritage. Recommended bird survey methods to inform impact assessment of onshore wind farms May. URL: http://surl.li/obym (2014) Accessed 28 Oct 2020

23. Sebastián-González E., Pérez-García J.M., Carrete M., Donázar J.A., Sánchez-Zapata J.A. Using network analysis to identify indicator species and reduce collision fatalities at wind farms. Biological Conservation, 224, 209-212. http://dx.doi.org/110.1016/j.biocon.2018.06.003 (2018)

24. Smith, J.A., Dwyer J.F. Avian interactions with renewable energy infrastructure: an update. Condor, 118, 411-423. (2016)

25. Yeremieiev, V., Osadchyi, V., Gorlov, P., \& Siokhin, V. Methodology for calculating the number of migratory birds in the territory of the wind farms of the Azov region using information and communication technology. In E3S Web of Conferences, 166, 1-8. (2020)

26. Wang, S., Wang, S., \& Smith, P. Ecological impacts of wind farms on birds: Questions, hypotheses, and research needs. Renewable and Sustainable Energy Reviews, 44, 599-607. (2015)

27. Winkelman, J. E. De invloed van de Sepproefwindcentrale te Oosterbierum (Fr.) op vogels. DLOInstituut voor Bos-en Natuuronderzoek. (1992) 